Article

\title{
Crystal Growth and Investigation of High-Pressure Physical Properties of $\mathrm{Fe}_{2} \mathrm{As}$
}

\author{
Guangyang Dai ${ }^{1,2}$, Changling Zhang ${ }^{1,2}$, Sijia Zhang ${ }^{1}$, Xin He ${ }^{1,2}$, Chongwen Ren ${ }^{1,2}$, \\ Jianfa Zhao ${ }^{1,2}$, Xiaodong $\mathrm{Li}^{3}{ }^{3}$, Xiancheng Wang ${ }^{1, *}$ and Changqing Jin ${ }^{1,2,4, *}$ \\ 1 Institute of Physics, Chinese Academy of Sciences, Beijing 100190, China; g.y.dai@iphy.ac.cn (G.D.); \\ clzhang@iphy.ac.cn (C.Z.); sjzhang@iphy.ac.cn (S.Z.); hexin2018@iphy.ac.cn (X.H.); \\ renchongwen@iphy.ac.cn (C.R.); zhaojf@iphy.ac.cn (J.Z.) \\ 2 School of Physics, University of Chinese Academy of Sciences, Beijing 100190, China \\ 3 Institute of High Energy Physics, Chinese Academy of Sciences, Beijing 100049, China; lixd@ihep.ac.cn \\ 4 Materials Research Laboratory at Songshan Lake, Dongguan 523808, China \\ * Correspondence: wangxiancheng@iphy.ac.cn (X.W.); Jin@iphy.ac.cn (C.J.)
}

Received: 9 August 2020; Accepted: 4 September 2020; Published: 6 September 2020

\begin{abstract}
We reported the growth of $\mathrm{Fe}_{2} \mathrm{As}$ single crystals and the study of its physical properties via comprehensive measurements, such as transport properties under pressure and high-pressure synchrotron radiation $\mathrm{X}$-ray diffraction. $\mathrm{Fe}_{2} \mathrm{As}$ is an antiferromagnetic metal with $T_{\mathrm{N}} \sim 355 \mathrm{~K}$. Within the pressure range of $100 \mathrm{GPa}$, no superconductivity was observed above $2 \mathrm{~K}$. The abrupt drop in resistance from 21 to $31.7 \mathrm{GPa}$ suggests a high-pressure phase transition happens. The high-pressure $X$-ray experiments indicate a new high-pressure phase appears, starting from 27.13 GPa. After the refinement of the high-pressure $\mathrm{X}$-ray data, the pressure dependence of lattice constants of $\mathrm{Fe}_{2} \mathrm{As}$ (P4/nmm phase) was plotted and the bulk modulus $\mathrm{B}_{0}$ was obtained to be 168.6 GPa.
\end{abstract}

Keywords: iron-based compound; high-pressure resistivity; high-pressure structure

\section{Introduction}

The discovery of the superconducting $\mathrm{LaO}_{1-x} \mathrm{~F}_{\mathrm{x}} \mathrm{FeAs}$ [1] with $\mathrm{Tc}=26 \mathrm{~K}$ has attracted great interest to search for new iron-based superconductors. Soon after this discovery, a series of iron-based layered oxypnictides $\mathrm{RFeAs}\left(\mathrm{O}_{1-x} \mathrm{~F}_{\mathrm{x}}\right)$ were found by replacing $\mathrm{La}$ atoms with other rare-earth elements $\mathrm{R}$ $(\mathrm{R}=\mathrm{Ce}, \mathrm{Pr}, \mathrm{Nd}, \mathrm{Sm}, . .$.$) [2-5]. The superconducting transition temperature was quickly enhanced to a$ maximum of $55 \mathrm{~K}$ in $\mathrm{SmO}_{1-x} \mathrm{~F}_{\mathrm{x}} \mathrm{FeAs}$ [4]. Subsequently, several families of iron-based superconductors were discovered, such as 122-type (Ba, K)Fe $\mathrm{As}_{2}$ [6], 11-type FeSe [7] and 111-type LiFeAs [8]. Iron-based superconductors contain the common $\mathrm{Fe}_{2 \times 2}(\mathrm{X}=\mathrm{As}$ and $\mathrm{Se})$ unit, which is believed to be crucial to support superconductivity in the iron-based materials. The superconductivity can be either induced by introducing charge carriers into the parent compounds or applying high pressure via suppressing the antiferromagnetic order [9-12]. Thus, the mechanism of superconductivity in iron-based compounds is considered to be highly related with the antiferromagnetic spin fluctuation.

$\mathrm{Fe}_{2}$ As crystallizes into a $\mathrm{Cu}_{2} \mathrm{Sb}$-type crystal structure. More interestingly, it contains [FeAs] layers, intercalated by Fe ions, and is isostructural to 111-type LiFeAs. For LiFeAs, there is no magnetic ordering and structural transition in compound LiFeAs, which makes it a special case in iron-based superconductors [13-15]. In contrast, $\mathrm{Fe}_{2} \mathrm{As}$ demonstrates an antiferromagnetic transition with a Néel temperature of about $353 \mathrm{~K}$ [16]. Therefore, it is possible for $\mathrm{Fe}_{2} \mathrm{As}$ to become a superconductor if the antiferromagnetic order is suppressed. High pressure was applied to $\mathrm{Fe}_{2} \mathrm{As}$ to explore the superconductivity within $32 \mathrm{GPa}$. However, no sign of superconductivity was observed [17,18]. In this work, we report on the study of properties of $\mathrm{Fe}_{2} \mathrm{As}$ within $100 \mathrm{GPa}$. $\mathrm{Fe}_{2} \mathrm{As}$ keeps its metallic state 
and no superconductivity is observed above $2 \mathrm{~K}$. It undergoes a high-pressure phase transition at about $27 \mathrm{GPa}$, which rules out the possibility of pressure-induced superconductivity in the tetragonal $P 4 / \mathrm{nmm}$ phase of $\mathrm{Fe}_{2} \mathrm{As}$. Via the study of high-pressure structure, the bulk modulus $\mathrm{B}_{0}$ for the $P 4 / \mathrm{nmm}$ phase of $\mathrm{Fe}_{2} \mathrm{As}$ is obtained to be about 168.6 GPa.

\section{Materials and Methods}

Single crystals of $\mathrm{Fe}_{2}$ As were grown using the self-flux method. High-purity Fe powder (Alfa, 99.999\%) and As powder (Alfa, 99.999\%) were mixed with a molar ratio of 2:1. Then the mixtures were put in an $\mathrm{Al}_{2} \mathrm{O}_{3}$ capsule, sealed into a niobium tube filled with high-purity $\mathrm{Ar}$ gas and then sealed in an evacuated quartz tube. The quartz tube was heated to $1180{ }^{\circ} \mathrm{C}$ at a rate of $4{ }^{\circ} \mathrm{C} / \mathrm{min}$ and hold at this temperature for $20 \mathrm{~h}$. Then, it was slowly cooled down to $600^{\circ} \mathrm{C}$ at a rate of $3{ }^{\circ} \mathrm{C} / \mathrm{h}$, after which the single crystals of $\mathrm{Fe}_{2}$ As with the typical size of $2 \mathrm{~mm}$ were obtained.

The samples were characterized by X-ray powder diffraction (XRD) in the $10^{\circ}-90^{\circ}$ range on a Philips X'pert diffractometer (PANalytical B.V., Almelo, The Netherlands) using $\mathrm{Cu} \mathrm{K} \alpha$ radiation generated at $40 \mathrm{kV}$ and $40 \mathrm{~mA}$. The chemical compositions were examined by energy dispersive $\mathrm{X}$-ray spectroscopy (EDX). The DC magnetic susceptibility was measured using a superconducting quantum interference device (SQUID) (Quantum Design, San Diego, CA, USA). The electrical resistivity under ambient pressure was measured by a physical property measurement system (PPMS) (Quantum Design, California, USA) using the four-probe method. The four Pt lines were pasted using silver conductive adhesive onto the flat surface ( $a b$-plane) of the single crystal sample, thus we could get the $a b$-plane resistance when current was applied in the $a b$-plane.

The electronic transport properties under high pressure were investigated using the four-probe electrical conductivity method as described in $[19,20]$. The dimension of the sample used in our measurement was about $35 \mu \mathrm{m} \times 35 \mu \mathrm{m}$ for the surface (ab-plane) of single crystal and $5 \mu \mathrm{m}$ thick, so that the four electrodes could be contacted tightly with the flat surface. $\mathrm{NaCl}$ powder was used as the pressure transmitting medium. The pressure was calibrated via the ruby fluorescence method at room temperature [21]. After being fully assembled, we put the diamond anvil cell inside a MagLab system (Oxford Instruments, Oxford, UK) to perform the electric transport experiments within the range of $2 \mathrm{~K}$ to $300 \mathrm{~K}$.

In situ high pressure synchrotron X-ray diffraction experiments were performed at Beijing Synchrotron Radiation Facility (Beijing, China) with a wavelength of $0.6199 \AA$ using a symmetric Mao Bell DAC (MHD Corporation, Fukuoka, Japan). Fine grounded polycrystalline powders were loaded in DAC and ruby balls were placed around the sample as pressure markers. The obtained two-dimensional image plate patterns were converted to one-dimensional $2 \theta$ versus intensity data using the Fit2D software package (Andy Hammersley, ESRF, Grenoble, France) [22]. Refinements of the high-pressure synchrotron X-ray diffraction patterns were performed by Rietveld method [23] through the GSAS package (Lansce Los Alamos, Los Alamos, NM, USA).

\section{Results and Discussion}

The compound $\mathrm{Fe}_{2} \mathrm{As}$ crystallizes into the $\mathrm{Cu}_{2} \mathrm{Sb}$-type crystal structure. Figure 1a shows the $\mathrm{X}$-ray diffraction (XRD) pattern of $\mathrm{Fe}_{2}$ As single crystal. Only sharp [00l] peaks can be observed, suggesting a good quality of our crystal sample. A Le Bail fit to the diffraction data yields $c=5.965 \AA$, which coincides with the previous result [24] and is much smaller than that of LiFeAs (c = 6.3574 $\AA$ ) [8]. The photograph of $\mathrm{Fe}_{2}$ As crystal with the size up to $1 \mathrm{~mm} \times 2 \mathrm{~mm} \times 0.5 \mathrm{~mm}$ is shown in the inset of Figure 1a. The elemental composition of the single crystal was checked by EDX, giving an average atomic ratio of Fe:As $=2.07: 1$, which is very close to the elemental ratio of stoichiometric $\mathrm{Fe}_{2} \mathrm{As}$. Figure $1 \mathrm{~b}$ shows the DC magnetic susceptibility measurements on $\mathrm{Fe}_{2} \mathrm{As}$ single crystal from $5 \mathrm{~K}$ to $380 \mathrm{~K}$ with applied magnetic field parallel to ab-plane in both zero-field cooled (ZFC) and field cooled (FC) modes. We can unambiguously find an antiferromagnetic transition at about $355 \mathrm{~K}$, which is in agreement with the result of magnetic susceptibility and neutron diffraction measurements [16]. 
Figure 1c shows the electrical resistivity versus temperature for $\mathrm{Fe}_{2} \mathrm{As}$ single crystal at ambient pressure. An anomaly at about $355 \mathrm{~K}$ can be observed in the resistivity curve, which can be attributed to the antiferromagnetic transition.
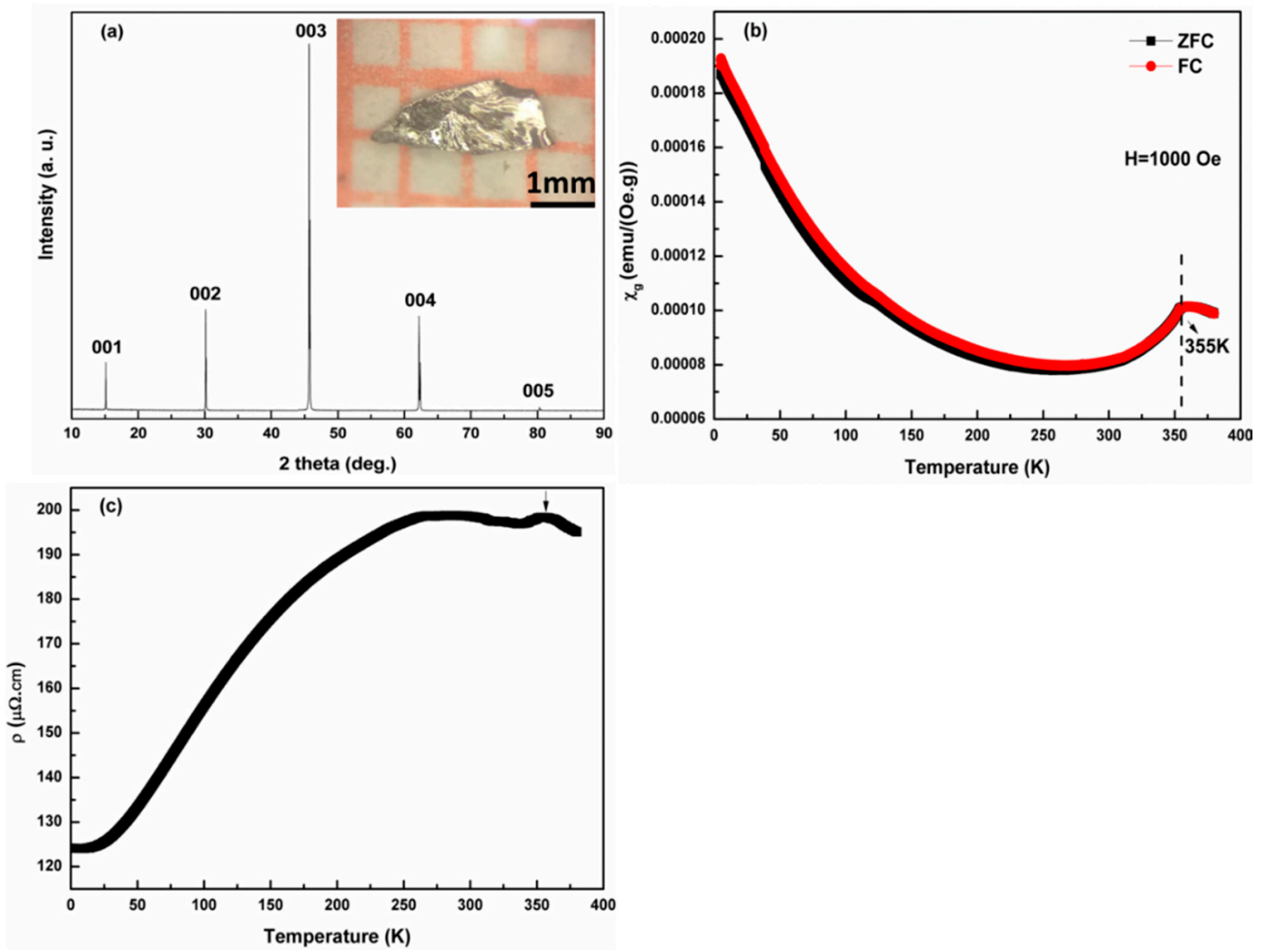

Figure 1. (a) X-ray diffraction (XRD) pattern of $\mathrm{Fe}_{2} \mathrm{As}$ single crystal. The inset shows the photograph of $\mathrm{Fe}_{2}$ As single crystal; (b) Zero-field cooled (ZFC) and field cooled (FC) susceptibilities versus temperature for $\mathrm{Fe}_{2} \mathrm{As}$ single crystal with applied magnetic field parallel to ab-plane, an obvious antiferromagnetic transition can be seen at about $355 \mathrm{~K}$; (c) Temperature dependence of $a b$ plane resistance at ambient pressure. An obvious anomaly at about $355 \mathrm{~K}$ in the resistivity curve was marked by arrow.

For the iron-based superconductors, superconductivity can always be induced by suppressing antiferromagnetic order. Pressure is a clean tool to suppress the antiferromagnetic order without introducing defects or impurities and, then, induce the possible superconductivity. The research on tuning superconductivity by pressure has been widely reported in many material systems ranging from topological materials to iron-based superconductors [25-33]. Therefore, we conducted the measurement of resistance for $\mathrm{Fe}_{2} \mathrm{As}$ within the range of $2 \mathrm{~K}$ to $300 \mathrm{~K}$, under pressure as high as $100 \mathrm{GPa}$, which can be seen in Figure 2. As reported before [17,18], it is difficult to determine the Néel temperature from the high-pressure resistance curve. Within the pressure range of $21 \mathrm{GPa}$, the resistance at low temperature increases as pressure increases, which should arise from the suppression of antiferromagnetic order and the enhancement of magnetic fluctuation. While within lower pressure the decrease in resistance with increasing pressure was reported in the references $[17,18]$. The disagreement is suggested to be caused by the difference in samples. In our work, single crystal was used for the resistance measurement and the data we got indicate $a b$-plane resistance, while the polycrystalline samples were used in the previous work where the extrinsic grains contacting resistance is included. When pressure increases from 21 to $31.7 \mathrm{GPa}$, the resistance drops abruptly. Generally, high-pressure phase has a more compacted structure and leads to a lower resistance. In addition, the new phase might completely destroy the antiferromagnetic order and push $\mathrm{Fe}_{2} \mathrm{As}$ away from antiferromagnetic fluctuation, which can also cause the drop in resistance. Therefore, it is hinted that the sharp drop in resistance is associated with the occurrence of pressure-induced structure transition as will be confirmed by the following high-pressure X-ray experiments. Above $31.7 \mathrm{GPa}$, the resistance gradually increases when further 
increasing the pressure. For $\mathrm{Fe}_{2} \mathrm{As}$, the anomaly of pressure dependence of resistance has also been observed in the pressure range from 10.4 to $31.4 \mathrm{GPa}$ in the previous work [17]. In any case, we cannot observe any sign of superconductivity above $2 \mathrm{~K}$ within our highest experimental pressure.
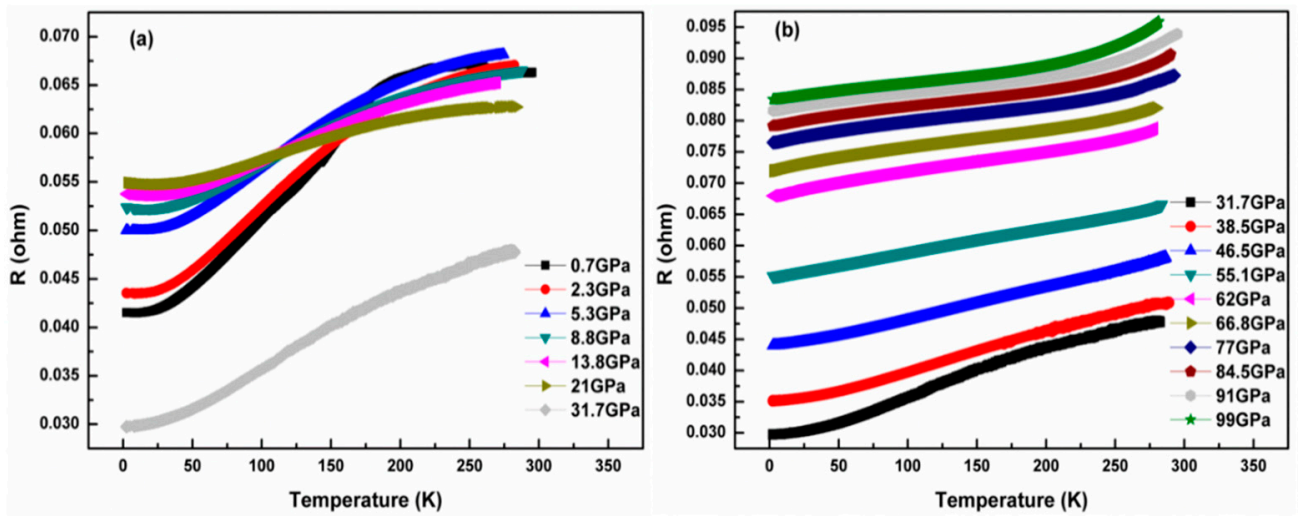

Figure 2. (a) Temperature dependence of $a b$-plane resistance at various pressures range from 0.7 to 31.7 $\mathrm{GPa}$; (b) Temperature dependence of $a b$-plane resistance at various pressures range from 31.7 to $99 \mathrm{GPa}$.

To examine the high-pressure phase transition, we carried out the high-pressure synchrotron radiation $X$-ray experiments. Figure 3 shows the $X$-ray diffraction patterns under high pressure. Below $23.5 \mathrm{GPa}$, all the peaks can be indexed very well as a tetragonal $\mathrm{P} 4 / \mathrm{nmm}$ phase. When the pressure increase up to $27.13 \mathrm{GPa}$, several peaks derived from $P 4 / \mathrm{nmm}$ phase become weak and disappear gradually. Simultaneously, there appears a set of new diffraction peaks marked with inverted triangles, as can be seen in Figure 3b, which indicates the appearance of the high-pressure phase. Further increasing the pressure, the high-pressure phase gradually becomes the main phase.
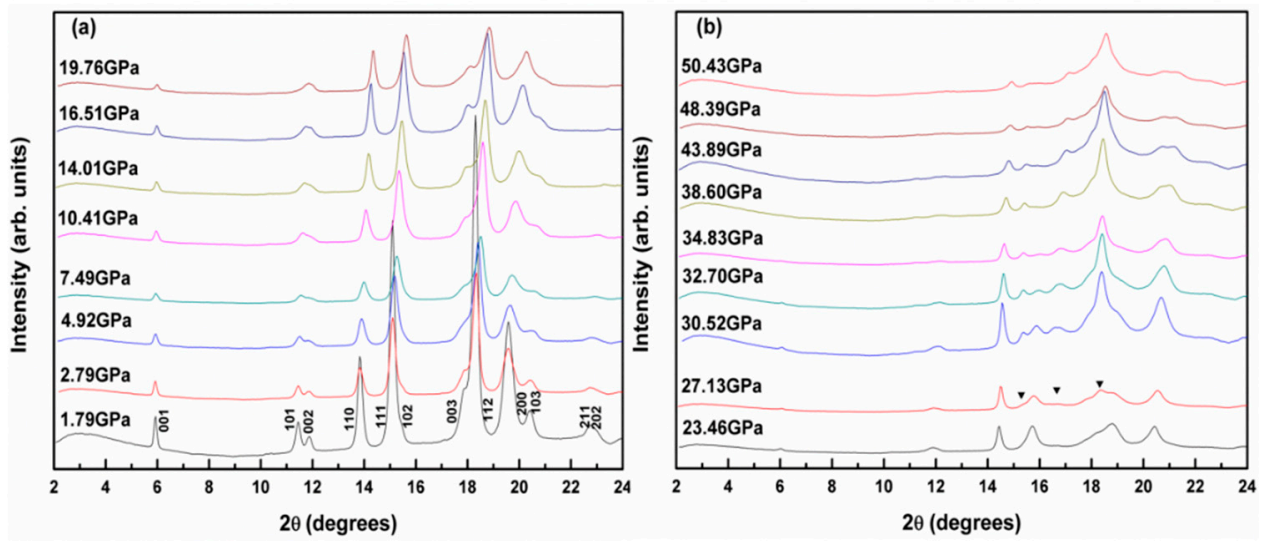

Figure 3. Synchrotron $\mathrm{X}$-ray diffraction patterns of $\mathrm{Fe}_{2} \mathrm{As}$ polycrystalline at different pressures up to $50.43 \mathrm{GPa}(\lambda=0.6199 \AA$ ). (a) XRD patterns at various pressures range from 1.79 to $19.76 \mathrm{GPa}$; (b) XRD patterns at various pressures range from 23.46 to $50.43 \mathrm{GPa}$, the peaks marked with inverted triangles denote the new diffraction peaks emerging.

Data analysis of the diffraction patterns was performed with the Rietveld refinements using the GSAS program package, from which we can obtain the values of lattice constants and unit cell volumes under different pressures for $P 4 / \mathrm{nmm}$ phase. As an example, Figure 4 presents the Rietveld refinements for the diffraction patterns at $1.79 \mathrm{GPa}$. The evolution of the lattice parameters with a pressure for $P 4 / \mathrm{nmm}$ phase is shown in Figure 5a. Both the lattice constants of $a$ and $c$ are compressed by pressure. Within $25 \mathrm{GPa}, a$ and $c$ shrink about $3.9 \%$ and $1.6 \%$, respectively; this demonstrates that the $a b$-plane is easier to be compressed than c axis. Figure $5 \mathrm{~b}$ presents the unit cell volumes versus pressure. The volume-pressure data are fitted using the third-order Birch-Murnaghan equation 
of states, $\mathrm{P}(\mathrm{GPa})=\frac{3}{2} \times \mathrm{B}_{0}\left[\left(\frac{\mathrm{V}_{0}}{\mathrm{~V}}\right)^{\frac{7}{3}}-\left(\frac{\mathrm{V}_{0}}{\mathrm{~V}}\right)^{\frac{5}{3}}\right] \times\left\{1-\left(3-\frac{3}{4} \times \mathrm{B}_{0}^{\prime}\right) \times\left[\left(\frac{\mathrm{V}_{0}}{\mathrm{~V}}\right)^{\frac{2}{3}}-1\right]\right\}$. When the first pressure derivative $\mathrm{B}_{0}{ }_{0}$ is fixed to be 4 , the fitting gives the value of bulk modulus $\mathrm{B}_{0}=168.6 \mathrm{GPa}$, which is higher than LiFeAs and close to that of CuFeAs [34].

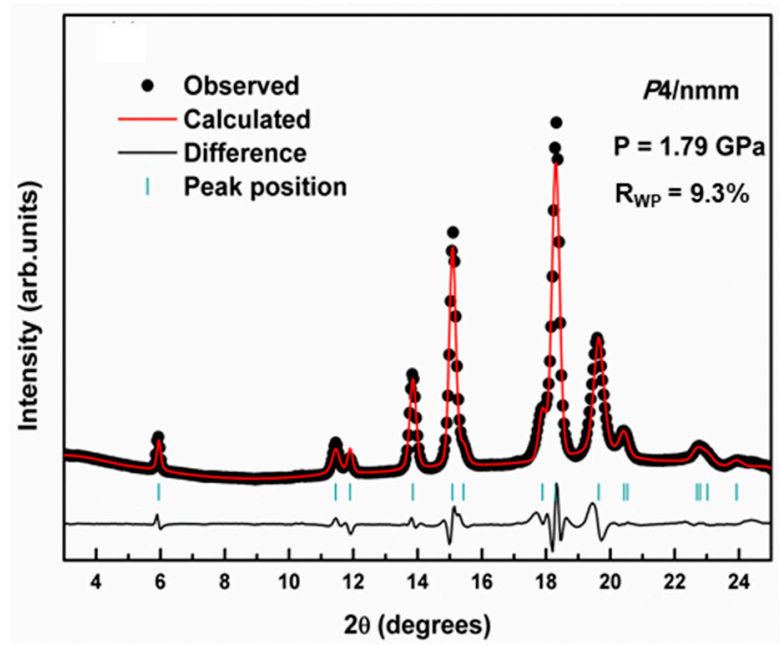

Figure 4. Rietveld refined XRD patterns of $\mathrm{Fe}_{2} \mathrm{As}$ at $1.79 \mathrm{GPa}$.
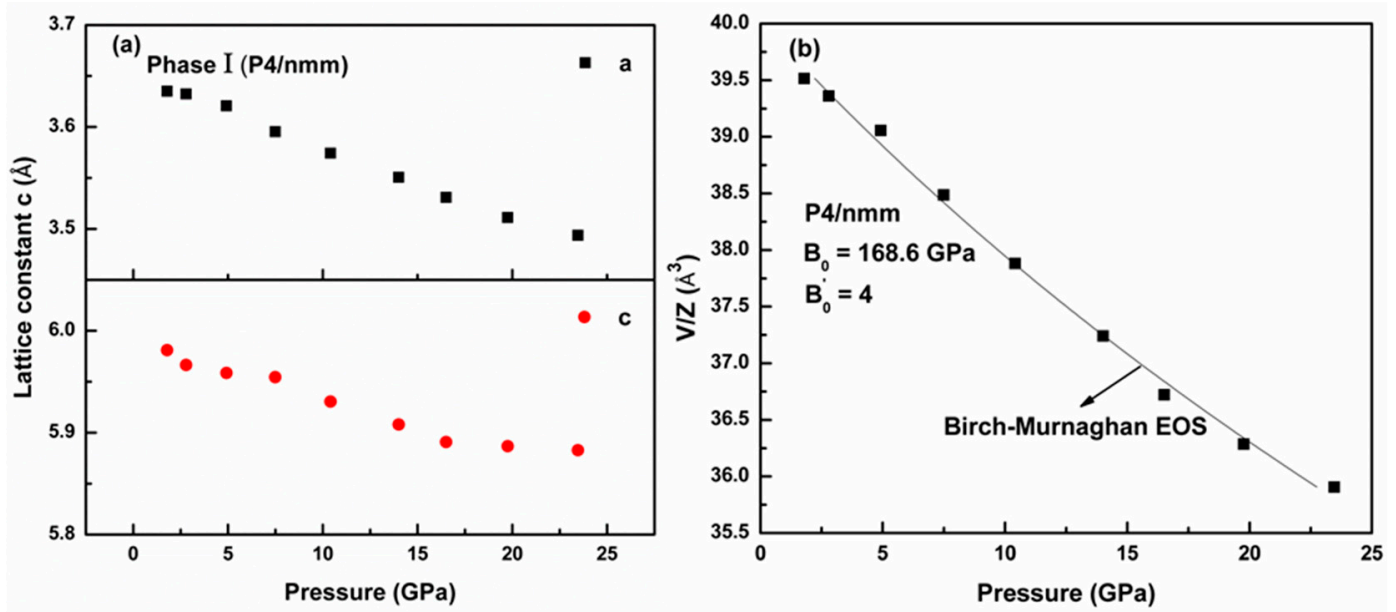

Figure 5. (a) Pressure dependence of the lattice constants $a$ and $c$ for $P 4 / \mathrm{nmm}$ phase; (b) Unit cell volumes versus pressure. The solid line shows the fitting curve using the third-order Birch-Murnaghan equation of states.

For the unknown high-pressure phase of $\mathrm{Fe}_{2} \mathrm{As}$, we can refer to the previous works about high-pressure phase transition for the isostructural "111" type iron based superconductors. NaFeAs has been reported to undergo an isostructural phase transition at $20 \mathrm{Gpa}$ [35]. Interestingly, the high-pressure crystal structures prediction of "111" type iron-based superconductors (LiFeAs, NaFeAs, and LiFeP) based on CALYPSO (Crystal structure Analysis by Particle Swarm Optimization) methodology indicates there exist two possible high-pressure crystal structures below $100 \mathrm{GPa}$, the $\mathrm{Cmcm}$ structure for $\mathrm{NaFeAs}$ or $\mathrm{LiFeP}$ and the $P-3 \mathrm{~m} 1$ structure for $\mathrm{LiFeAs}$ [36]. However, using either $\mathrm{Cmcm}$ or $P-3 \mathrm{~m} 1$ structure as the initial model to carry out the refinements for our high-pressure $X$-ray data, we found that the peaks of high-pressure phase cannot be well fitted. Thus, the high-pressure phase of $\mathrm{Fe}_{2} \mathrm{As}$ needs further studies to be determined. In any case, the high-pressure phase transition rules out the possibility of pressure-induced superconductivity in the tetragonal $P 4 / \mathrm{nmm}$ phase of $\mathrm{Fe}_{2} \mathrm{As}$. 


\section{Conclusions}

In this work, high quality single crystals of $\mathrm{Fe}_{2} \mathrm{As}$ were grown and the properties under high pressure were studied. Within $100 \mathrm{GPa}, \mathrm{Fe}_{2}$ As keeps its metallic state and no superconductivity is observed above $2 \mathrm{~K}$. A high-pressure phase transition happens at about $27 \mathrm{GPa}$, which suggests that pressure-induced superconductivity cannot be observed in the tetragonal $P 4 / \mathrm{nmm}$ phase of $\mathrm{Fe}_{2} \mathrm{As}$. At last, via the study of structure under high pressure we obtained the bulk modulus $\mathrm{B}_{0}$ of about 168.6 GPa for the ambient phase of $\mathrm{Fe}_{2}$ As.

Author Contributions: X.W. and C.J. conceived and designed the experiments and edited the manuscript; G.D. performed the experiments, analyzed the data and drafted the manuscript; C.Z. and S.Z. contributed the initial high-pressure resistivity measurements; X.H., C.R., J.Z. and X.L. contributed the high-pressure synchrotron radiation $X$-ray experiments. All authors have read and agreed to the published version of the manuscript.

Funding: This work was financially supported by the National Science Foundation of China (NSFC) and the National Basic Research Program of China.

Conflicts of Interest: The authors declare no conflict of interest.

\section{References}

1. Kamihara, Y.; Watanabe, T.; Hirano, M.; Hosono, H. Iron-based layered superconductor La[O $\left.{ }_{1-x} F_{x}\right] F e A s$ $(\mathrm{x}=0.05-0.12)$ with Tc $=26$ K. J. Am. Chem. Soc. 2008, 130, 3296-3297. [CrossRef] [PubMed]

2. Takahashi, H.; Igawa, K.; Arii, K.; Kamihara, Y.; Hirano, M.; Hosono, H. Superconductivity at $43 \mathrm{~K}$ in an iron-based layered compound $\mathrm{LaO}_{1-x} \mathrm{~F}_{\mathrm{x}} \mathrm{FeAs}$. Nature 2008, 453, 376-378. [CrossRef] [PubMed]

3. Chen, X.H.; Wu, T.; Wu, G.; Liu, R.H.; Chen, H.; Fang, D.F. Superconductivity at $43 \mathrm{~K}$ in $\mathrm{SmFeAsO}_{1-\mathrm{x}} \mathrm{F}_{\mathrm{x}}$. Nature 2008, 453, 761-762. [CrossRef] [PubMed]

4. Ren, Z.A.; Lu, W.; Yang, J.; Yi, W.; Shen, X.L.; Zheng, C.; Che, G.C.; Dong, X.L.; Sun, L.L.; Zhou, F.; et al.

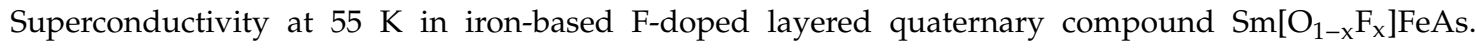
Chin. Phys. Lett. 2008, 25, 2215-2216.

5. Chen, G.F.; Li, Z.; Wu, D.; Li, G.; Hu, W.Z.; Dong, J.; Zheng, P.; Luo, J.L.; Wang, N.L. Superconductivity at $41 \mathrm{~K}$ and its competition with spin-density-wave instability in layered $\mathrm{CeO}_{1-x} \mathrm{~F}_{\mathrm{x}} \mathrm{FeAs}$. Phys. Rev. Lett. 2008, 100, 247002. [CrossRef]

6. Rotter, M.; Tegel, M.; Johrendt, D. Superconductivity at $38 \mathrm{~K}$ in the iron arsenide $\left(\mathrm{Ba}_{1-\mathrm{x}} \mathrm{K}_{\mathrm{x}}\right) \mathrm{Fe}_{2} \mathrm{As}_{2}$. Phys. Rev. Lett. 2008, 101, 107006. [CrossRef]

7. Hsu, F.C.; Luo, J.Y.; Yeh, K.W.; Chen, T.K.; Huang, T.W.; Wu, P.M.; Lee, Y.C.; Huang, Y.L.; Chu, Y.Y.; Yan, D.C.; et al. Superconductivity in the PbO-type structure alpha-FeSe. Proc. Natl. Acad. Sci. USA 2008, 105, 14262-14264. [CrossRef]

8. Wang, X.C.; Liu, Q.Q.; Lv, Q.Q.; Gao, W.B.; Yang, L.X.; Yu, R.C.; Li, F.Y.; Jin, C.Q. The superconductivity at $18 \mathrm{~K}$ in LiFeAs system. Solid State Commun. 2008, 148, 538-540. [CrossRef]

9. Sefat, A.S.; Jin, R.; McGuire, M.A.; Sales, B.C.; Singh, D.J.; Mandrus, D. Superconductivity at 22 K in Co-Doped $\mathrm{BaFe}_{2} \mathrm{As}_{2}$ Crystals. Phys. Rev. Lett. 2008, 101, 117004. [CrossRef]

10. Torikachvili, M.S.; Bud'ko, S.L.; Ni, N.; Canfield, P.C. Pressure Induced Superconductivity in $\mathrm{CaFe}_{2} \mathrm{As}_{2}$. Phys. Rev. Lett. 2008, 101, 057006. [CrossRef]

11. Igawa, K.; Okada, H.; Takahashi, H.; Matsuishi, S.; Kamihara, Y.; Hirano, M.; Hosono, H.; Matsubayashi, K.; Uwatoko, Y. Pressure-Induced Superconductivity in Iron Pnictide Compound $\mathrm{SrFe}_{2} \mathrm{As}_{2}$. J. Phys. Soc. Jpn. 2009, 78, 025001. [CrossRef]

12. Matsubayashi, K.; Katayama, N.; Ohgushi, K.; Yamada, A.; Munakata, K.; Matsumoto, T.; Uwatoko, Y. Intrinsic Properties of $\mathrm{AFe}_{2} \mathrm{As}_{2}(\mathrm{~A}=\mathrm{Ba}, \mathrm{Sr})$ Single Crystal under Highly Hydrostatic Pressure Conditions. J. Phys. Soc. Jpn. 2009, 78, 073706. [CrossRef]

13. Zhang, P.; Wang, Z.J.; Wu, X.X.; Yaji, K.; Ishida, Y.; Kohama, Y.; Dai, G.Y.; Sun, Y.; Bareille, C.; Kuroda, K.; et al. Multiple topological states in iron-based superconductors. Nat. Phys. 2019, 15, 41-47. [CrossRef]

14. Yin, J.X.; Zhang, S.S.; Dai, G.Y.; Zhao, Y.Y.; Kreisel, A.; Macam, G.; Wu, X.X.; Miao, H.; Huang, Z.Q.; Martiny, J.H.J.; et al. Quantum phase transition of correlated iron-based superconductivity in $\mathrm{LiFe}_{1-\mathrm{x}} \mathrm{Co}_{\mathrm{x}} \mathrm{As}$. Phys. Rev. Lett. 2019, 123, 217004. [CrossRef] [PubMed] 
15. Xu, Z.; Dai, G.Y.; Li, Y.; Yin, Z.P.; Rong, Y.; Tian, L.; Liu, P.P.; Wang, H.; Xing, L.Y.; Wei, Y.; et al. Strong local moment antiferromagnetic spin fluctuations in V-doped LiFeAs. npj Quantum Mater. 2020, 5, 11. [CrossRef]

16. Katsuraki, H.; Achiwa, N. The Magnetic structure of $\mathrm{Fe}_{2}$ As. J. Phys. Soc. Jpn. 1966, 21, 2238-2243. [CrossRef]

17. Zocco, D.A.; Tutun, D.Y.; Hamlin, J.J.; Jeffries, J.R.; Weir, S.T.; Vohra, Y.K.; Maple, M.B. High pressure transport studies of the LiFeAs analogs $\mathrm{CuFeTe}_{2}$ and $\mathrm{Fe}_{2}$ As. Supercond. Sci. Technol. 2012, 25, 084018. [CrossRef]

18. Takeshita, N.; Iyo, A.; Ishida, S.; Eisaki, H.; Yoshida, Y. Electrical resistivity of FeAs, $\mathrm{FeAs}_{2}$ and $\mathrm{Fe}_{2} \mathrm{As}$ at homogeneous high pressures. J. Phys. Conf. Ser. 2017, 950, 042024. [CrossRef]

19. Zhang, J.L.; Zhang, S.J.; Weng, H.M.; Zhang, W.; Yang, L.X.; Liu, Q.Q.; Feng, S.M.; Wang, X.C.; Yu, R.C.; Cao, L.Z.; et al. Pressure-induced superconductivity in topological parent compound $\mathrm{Bi}_{2} \mathrm{Te}_{3}$. Proc. Natl. Acad. Sci. USA 2011, 108, 24-28. [CrossRef]

20. Zhang, S.J.; Zhang, J.L.; Yu, X.H.; Zhu, J.; Kong, P.P.; Feng, S.M.; Liu, Q.Q.; Yang, L.X.; Wang, X.C.; Cao, L.Z.; et al. The comprehensive phase evolution for $\mathrm{Bi}_{2} \mathrm{Te}_{3}$ topological compound as function of pressure. J. Appl. Phys. 2012, 111, 112630. [CrossRef]

21. Mao, H.; Xu, J.A.; Bell, P. Calibration of the ruby pressure gauge to $800 \mathrm{kbar}$ under quasi-hydrostatic conditions. J. Geophys. Res. Solid Earth Plantets 1986, 91, 4673-4676. [CrossRef]

22. Hammersley, A.P.; Svensson, S.O.; Hanfland, M.; Fitch, A.N.; Hausermann, D. Two-dimensional detector software: From real detector to idealized image or two-theta scan. Int. J. High Press. Res. 1996, 14, 235-248. [CrossRef]

23. Toby, B.H. EXPGUI, a graphical user interface for GSAS. J. Appl. Cryst. 2001, 34, 210-213. [CrossRef]

24. Nuss, J.; Wedig, U.; Jansen, M. Geometric variations and electron localizations in intermetallics: PbFCl type compounds. Z. Krist. 2006, 221, 554-562. [CrossRef]

25. Kong, P.P.; Zhang, J.L.; Zhang, S.J.; Zhu, J.; Liu, Q.Q.; Yu, R.C.; Fang, Z.; Jin, C.Q.; Yang, W.G.; Yu, X.H.; et al. Superconductivity of the topological insulator $\mathrm{Bi}_{2} \mathrm{Se}_{3}$ at high pressure. J. Phys. Condens. Matter 2013, 25, 362204. [CrossRef]

26. Zhu, J.; Zhang, J.L.; Kong, P.P.; Zhang, S.J.; Yu, X.H.; Zhu, J.L.; Liu, Q.Q.; Li, X.; Yu, R.C.; Ahuja, R.; et al. Superconductivity in Topological Insulator $\mathrm{Sb}_{2} \mathrm{Te}_{3}$ Induced by Pressure. Sci. Rep. 2013, 3, 2016. [CrossRef]

27. Liu, Y.; Long, Y.J.; Zhao, L.X.; Nie, S.M.; Zhang, S.J.; Weng, Y.X.; Jin, M.L.; Li, W.M.; Liu, Q.Q.; Long, Y.W.; et al. Superconductivity in $\mathrm{HfTe}_{5}$ across weak to strong topological insulator transition induced via pressures. Sci. Rep. 2017, 7, 44367. [CrossRef]

28. Jin, M.L.; Sun, F.; Xing, L.Y.; Zhang, S.J.; Feng, S.M.; Kong, P.P.; Li, W.M.; Wang, X.C.; Zhu, J.L.; Long, Y.W.; et al. Superconductivity Bordering Rashba Type Topological Transition. Sci. Rep. 2017, 7, 39699. [CrossRef]

29. Okada, H.; Igawa, K.; Takahashi, H.; Kamihara, Y.; Hirano, M.; Hosono, H.; Matsubayashi, K.; Uwatoko, Y. Superconductivity under high pressure in LaFeAsO. J. Phys. Soc. Jpn. 2008, 77, 113712. [CrossRef]

30. Mani, A.; Ghosh, N.; Paulraj, S.; Bharathi, A.; Sundar, C.S. Pressure-induced superconductivity in $\mathrm{BaFe}_{2} \mathrm{As}_{2}$ single crystal. Europhys. Lett. 2009, 87, 17004. [CrossRef]

31. Wu, J.J.; Lin, J.F.; Wang, X.C.; Liu, Q.Q.; Zhu, J.L.; Xiao, Y.M.; Chow, P.; Jin, C.Q. Pressure-decoupled magnetic and structural transitions of the parent compound of iron-based 122 superconductors $\mathrm{BaFe}_{2} \mathrm{As}_{2}$. Proc. Natl. Acad. Sci. USA 2013, 110, 17263-17266. [CrossRef] [PubMed]

32. Wang, X.C.; Zhang, S.J.; Liu, Q.Q.; Deng, Z.; Lv, Y.X.; Zhu, J.L.; Feng, S.M.; Jin, C.Q. Effect of pressure on a "111"-type iron pnictide superconductor. High Press. Res. 2011, 31, 7-12. [CrossRef]

33. Mizuguchi, Y.; Tomioka, F.; Tsuda, S.; Yamaguchi, T.; Takano, Y. Superconductivity at $27 \mathrm{~K}$ in tetragonal FeSe under high pressure. Appl. Phys. Lett. 2008, 93, 152505. [CrossRef]

34. Chen, Z.J.; Xu, G.B.; Yan, J.G.; Kuang, Z.; Chen, T.H.; Li, D.H. First-principles investigation of mechanical and electronic properties of MFeAs $(\mathrm{M}=\mathrm{Cu}, \mathrm{Li}$, and Na). J. Appl. Phys. 2016, 120, 235103. [CrossRef]

35. Liu, Q.Q.; Yu, X.H.; Wang, X.C.; Deng, Z.; Lv, Y.X.; Zhu, J.L.; Zhang, S.J.; Liu, H.Z.; Yang, W.G.; Wang, L.; et al. Pressure-Induced isostructural phase transition and correlation of feas coordination with the superconducting properties of 111-Type $\mathrm{Na}_{1-\mathrm{x}}$ FeAs. J. Am. Chem. Soc. 2011, 133, 7892-7896. [CrossRef]

36. Zhang, X.X.; Wang, Y.C.; Ma, Y.M. High pressure structures of "111" type iron-based superconductors predicted from first-principles. Phys. Chem. Chem. Phys. 2012, 14, 15029-15035. [CrossRef]

(C) 2020 by the authors. Licensee MDPI, Basel, Switzerland. This article is an open access article distributed under the terms and conditions of the Creative Commons Attribution (CC BY) license (http://creativecommons.org/licenses/by/4.0/). 